\title{
Protein expression in the midgut of sugar-fed Aedes albopictus females
}

Leonardo Saboia-Vahia ${ }^{1}$, Andre Borges-Veloso ${ }^{1}$, Patricia Cuervo², Magno Junqueira ${ }^{5}$, Camila Mesquita-Rodrigues ${ }^{1}$, Constanca Britto ${ }^{1}$, Gilberto Barbosa Domont ${ }^{3^{*}}$ and Jose Batista De Jesus ${ }^{1,4^{*}}$

\begin{abstract}
Background: Aedes albopictus is a vector for several fatal arboviruses in tropical and sub-tropical regions of the world. The midgut of the mosquito is the first barrier that pathogens must overcome to establish infection and represents one of the main immunologically active sites of the insect. Nevertheless, little is known about the proteins involved in the defense against pathogens, and even in the processing of food, and the detoxification of metabolites. The identification of proteins exclusively expressed in the midgut is the first step in understanding the complex physiology of this tissue and can provide insight into the mechanisms of pathogen-vector interaction. However, identification of the locally expressed proteins presents a challenge because the Ae. albopictus genome has not been sequenced.

Methods: In this study, two-dimensional electrophoresis (2DE) was combined with liquid chromatography in line with tandem mass spectrometry (LC-MS/MS) and data mining to identify the major proteins in the midgut of sugar-fed Ae. albopictus females.

Results: Fifty-six proteins were identified by sequence similarity to entries from the Ae. aegypti genome. In addition, two hypothetical proteins were experimentally confirmed. According to the gene ontology analysis, the identified proteins were classified into 16 clusters of biological processes. Use of the STRING database to investigate protein functional associations revealed five functional networks among the identified proteins, including a network for carbohydrate and amino acid metabolism, a group associated with ATP production and a network of proteins that interact during detoxification of toxic free radicals, among others. This analysis allowed the assignment of a potential role for proteins with unknown function based on their functional association with other characterized proteins.
\end{abstract}

Conclusion: Our findings represent the first proteome map of the Ae. albopictus midgut and denotes the first steps towards the description of a comprehensive proteome map of this vector. In addition, the data contributes to the functional annotation of Aedes spp. genomes using mass spectrometry-based proteomics data combined with complementary gene prediction methods.

Keywords: Aedes albopictus, Culicidae, Midgut, Proteomics, Proteome, Two-dimensional electrophoresis, Mass spectrometry

\footnotetext{
*Correspondence: gilberto@iq.ufrj.br; jbj@ioc.fiocruz.br

${ }^{3}$ Unidade de Proteômica, Laboratório de Química de Proteínas, Instituto de

Química, Universidade Federal do Rio de Janeiro, Rio de Janeiro, Brazil

'Laboratório de Biologia Molecular e Doenças Endêmicas, Instituto Oswaldo

Cruz, FIOCRUZ, Rio de Janeiro, Brazil

Full list of author information is available at the end of the article
}

\section{( Biomed Central}

(c) 2012 Saboia-Vahia et al.; licensee BioMed Central Ltd. This is an Open Access article distributed under the terms of the Creative Commons Attribution License (http://creativecommons.org/licenses/by/2.0), which permits unrestricted use, distribution, and reproduction in any medium, provided the original work is properly cited. 


\section{Background}

The mosquito Aedes albopictus is a vector of fatal arboviruses such as yellow fever, Chikungunya and Dengue, which, according to estimates made by the World Health Organization (WHO) can reach over 50 million cases worldwide each year [1-3]. In Brazil, Ae. albopictus has been reported in 21 states with 1,502 municipalities infested [4]. This distribution is consistent with the fact that this species is able to adapt easily to new habitats, particularly those disturbed by man, such as wooded areas occupied by new settlements, and over time, becomes a permanent part of the local fauna [5]. During blood feeding females of Ae. albopictus acquire the nutrients necessary for egg maturation and production of yolk proteins [6]. However, during such feeding, females can also be infected with various pathogens, such as Dengue virus, which must cross the midgut epithelial cells to finally reach the salivary glands and ensure their transmission to a new host during the next blood meal. For this reason, many previous studies have focused on the salivary glands with the aim of discovering biomarkers involved in the interaction of tissue cells with the virus or parasite and identifying molecules involved in immune responses at the time of the insect blood meal [7-11]. However, the midgut is the first barrier that pathogens must overcome to establish infection and represents one of the main immunologically active sites of the insect [12]. Thus, many elements including the blood of the vertebrate to be processed, pathogens and the molecules of the vector immune response, among others, converge on the midgut. Nevertheless, little is known about the proteins involved in processing the blood or detoxifying the metabolites from this process. Furthermore, the extent of the proteins involved in defense against pathogens and which are expressed during the mosquito feeding intervals are also unknown. A description of these molecules may help to understand the phenomena that control the development of pathogens and subsequent transmission by the insect. Characterizing the profile of proteins in the midgut of females is one of the first steps to comprehend the complex physiology of this tissue. Proteomic approaches enable the protein profile of a tissue or cell to be fully defined and the proteins expressed under different conditions to be identified. Transcriptomic analyses have made important contributions to understanding the biology of Aedes spp., but few proteomic studies have been conducted in this genus. However, proteomic techniques have been used to characterize Ae. aegypti subproteomes, such as membrane from larval midgut, adult salivary gland, Malpighian tubules and semen [13-16]. In addition, a proteomic analysis of an Ae. albopictus cell line infected by Dengue serotypes 1 and 3 has been reported [17]. In the present study, using an approach that combines two-dimensional electrophoresis, mass spectrometry and data mining, we describe the proteomic map of the midgut from Ae. albopictus females.

\section{Methods \\ Chemicals}

All reagents were purchased from Sigma (St. Louis, MO, USA) or Merck (São Paulo, SP, Brazil). MilliQ-purified water (Millipore Corp., Bedford, MA, USA) was used to make all of the solutions.

\section{Insects}

Experiments were carried out using female adults (2-5 days old) of Ae. albopictus caught in the Brazilian state of Rio de Janeiro and reared in a closed colony in the Laboratório de Transmissores de Hematozoários - Instituto Oswaldo Cruz, FIOCRUZ, Rio de Janeiro. Mosquitoes used in this study had been maintained for near 100 generations in the closed colony. Laboratory maintenance conditions were a temperature of $25 \pm 1^{\circ} \mathrm{C}$, relative humidity $60 \pm 10 \%$ and a light:dark photoperiod of 14:10 h. The mosquitoes were maintained on a $10 \%$ sucrose diet.

\section{Gut dissection}

The mosquitoes were cold-anesthetized on ice and decapitated. Dissection was performed in cold, sterilized PBS buffer, pH 7.4 (150 mM NaCl, $\left.10 \mathrm{mM} \mathrm{Na} 2 \mathrm{HPO}_{4}\right)$. The thorax was held with forceps (\#5), and the intestine, Malpighian tubules and ovary were dissected by gently pulling at the rectum with another pair of forceps. In order to guarantee the integrity and cleanliness of the midguts, the Malpighian tubules and ovaries were cut out, and the midguts were cut by a longitudinal incision and thoroughly rinsed with PBS to remove the gut contents, including bacteria present as general microbiota. Midguts were then transferred to a microcentrifuge tube. The isolated midguts were digitally imaged using optic microscopy with differential interference contrast.

\section{Protein extraction}

A pool of 50 midguts was lysed in IEF buffer containing $9 \mathrm{M}$ urea, 4\% CHAPS, $65 \mathrm{mM}$ dithiothreitol (DTT), and $1 \%$ ampholytes (pH 3-10) plus $5 \mathrm{mM}$ PMSF and a cocktail of protease inhibitors. The samples were mechanically lysed using a plastic pestle in combination with 10 cycles of freezing in liquid nitrogen and thawing. The lysate was centrifuged at $10,000 \times \mathrm{g}$ for $10 \mathrm{~min}$ at $4^{\circ} \mathrm{C}$, and the proteins in the resulting supernatant were precipitated with methanol:chloroform (3:1). Finally, the pellet was resuspended in IEF buffer ( $9 \mathrm{M}$ urea, $4 \%$ CHAPS, $65 \mathrm{mM}$ dithiothreitol (DTT) and 1\% ampholytes, $\mathrm{pH} 3-10$ ) for $1 \mathrm{~h}$ at room temperature. The protein concentration was determined using the 2-D Quant Kit (GE Healthcare). 


\section{DE electrophoresis, protein visualization and image analysis}

For the first dimension, $100 \mu \mathrm{g}$ of the protein was diluted to a final volume of $125 \mu \mathrm{l}$ in a rehydration solution (8 M urea, 2\% CHAPS, 65 mM DTT, 1.5\% ampholytes, $\mathrm{pH} 3-10$, and $0.001 \%$ bromophenol blue). This solution was applied to IEF strips $(7 \mathrm{~cm}, \mathrm{pH} 3-10$ nonlinear; GE Healthcare) and submitted to isoelectric focusing on an Ettan IPGphor 3 (GE Healthcare) at $20^{\circ} \mathrm{C}$ with a maximum current of $50 \mu \mathrm{A} /$ strip. The focusing parameters were set as previously described [18]. Reduced $(10 \mathrm{mg} / \mathrm{mL}$ DTT) and alkylated (25 mg/mL iodoacetamide) proteins were separated on 12\% SDS-PAGE gels (30\% acrylamide, $0.8 \%$ bis-acrylamide) using a vertical system (Bio-Rad) and standard Tris/glycine/SDS buffer. The gels were stained with colloidal Coomassie Brilliant Blue G-250 [19]. Images of the gels were acquired using a GS- $800^{\mathrm{Tm}}$ calibrated imaging densitometer (Bio-Rad), and image analysis was performed using PDQuest ${ }^{\mathrm{TM}}$ software (Bio-Rad). Three gels from three independent gut suspensions were compared. To assign experimental $\mathrm{p} I$ and $\mathrm{Mr}$ coordinates for each single spot, 2DE gels were calibrated using a select set of reliable identification landmarks distributed throughout the entire gel.

\section{Protein digestion, peptide extraction and analysis by mass spectrometry}

The protein spots were manually excised and digested following previously described protocols $[18,20]$. Briefly, the gel pieces were washed with $50 \%(\mathrm{v} / \mathrm{v})$ acetonitrile in $25 \mathrm{mM}$ ammonium bicarbonate, dehydrated in $100 \%$ acetonitrile, dried and further rehydrated in $50 \mathrm{mM}$ ammonium bicarbonate with 200 ng of trypsin (Promega). The tryptic digestion was performed overnight at $37^{\circ} \mathrm{C}$. The peptides were extracted using $0.1 \%$ formic acid in $50 \%(\mathrm{v} / \mathrm{v})$ acetonitrile, concentrated under vacuum and desalted using C18 tips. The eluted peptides were loaded in a nanoLC (Nano-LC Ultra 2D Plus, Eksigent), running a 50 minute gradient. Peptides were fractionated using a gradient from 95\% phase A (95\% water, 5\% Acetonitrile, $0.1 \%$ formic acid added to the total) to $40 \%$ phase B (85\% Acetonitrile, 15\% water, 0.1\% formic acid added to the total) for $42 \mathrm{~min}, 40 \%$ to $90 \%$ phase B during 4 minutes and sustaining $90 \%$ phase B for another 4 minutes (total of $50 \mathrm{~min}$ at a flow rate of $200 \mathrm{nl} / \mathrm{min}$ ). Analytical column consisted of ReproSIL Gold c18 3 um diameter beads (Dr Maisch GmbH, Germany) packed in-house inside a 75 um ID silica tip with metalic coating, $12 \mathrm{~cm}$ length. The nanoLC was in-line with a hybrid LTQ XL-Orbitrap mass spectrometer, running a Data Dependent Acquisition method, where MS1 was performed on the FTMS at 60000 resolution, followed by CID fragmentation (35 normalized collisional energy) of the 5 most intense ion analyzed on the ITMS with a dynamic exclusion of 90 seconds to prevent re-fragmentation of the same ion. The mass spectra were searched against the non-redundant database of the National Center for Biotechnology (NCBI) using the program Mascot MS/MS ion search (www. matrixscience.com/search_form_select.html, Matrix Science, Oxford, UK, free online version). The search parameters were lack of taxonomic restrictions; one tryptic miscleavage; carbamidomethylation of cysteine residues as fixed and oxidation of methionine and acetylation as variable modifications; $10 \mathrm{ppm}$ mass tolerance for the MS mode and 0.6 Da tolerance for its corresponding fragments in MS/MS.

\section{Bioinformatics analyses of identified proteins}

Gene Ontology (GO) annotations of biological process of Ae albopictus proteins were assigned according to those reported in the VectorBase database (http://www. vectorbase.org/) and confirmed at the AmiGO database (http://amigo.geneontology.org/cgi-bin/amigo/search. cgi). The putative function of hypothetical proteins was inferred using the InterProScan Sequence Search (http:// www.ebi.ac.uk/Tools/pfa/iprscan/). Identified proteins were also analyzed in terms of putative functional association networks according to the STRING 9.0 Server [21,22] (http://www.string-db.org).

\section{Results and discussion}

Two-dimensional gel separation and identification of $A e$. albopictus gut proteins

The gut proteins were fractionated by $2 \mathrm{DE}$ in a non-linear gradient $\mathrm{pH} 3-10$. Image analysis of $2 \mathrm{DE}$ gels obtained from three independent experiments showed that the protein spot profiles were highly reproducible in terms of both the total number of protein spots and their relative positions and intensities. Approximately 340 protein spots, distributed in a molecular mass range between $\sim 17$ and $\sim 110 \mathrm{kDa}$ and a $\mathrm{p} I$ range between $\sim 3.5$ and $\sim 9.5$, were detected in the Coomassie blue G-stained gels (Figure 1). These results agree with previously reported proteomic maps of Ae. aegypti midgut where a similar number of spots were resolved $[13,14])$. In the absence of reported Ae. albopictus genome sequences, the proteins were identified based on their similarity with the available Ae. aegypti sequences. Automatic search of tandem mass spectra allowed the identification of 56 proteins from 26 protein spots (Table 1, Figure 1). Forty different protein entries were found among the 56 identifications (Tables 1 and 2). The spot numbers in Table 1 correspond to the midgut proteins shown in Figure 1.

By comparing our data to the previously reported protein profiles of the midgut and midgut brush border membrane vesicles 2D maps of Ae aegypti [14,23], we identified approximately 60\% (25/40) and 47\% (19/40) of the proteins, respectively, for the first time in the midgut 


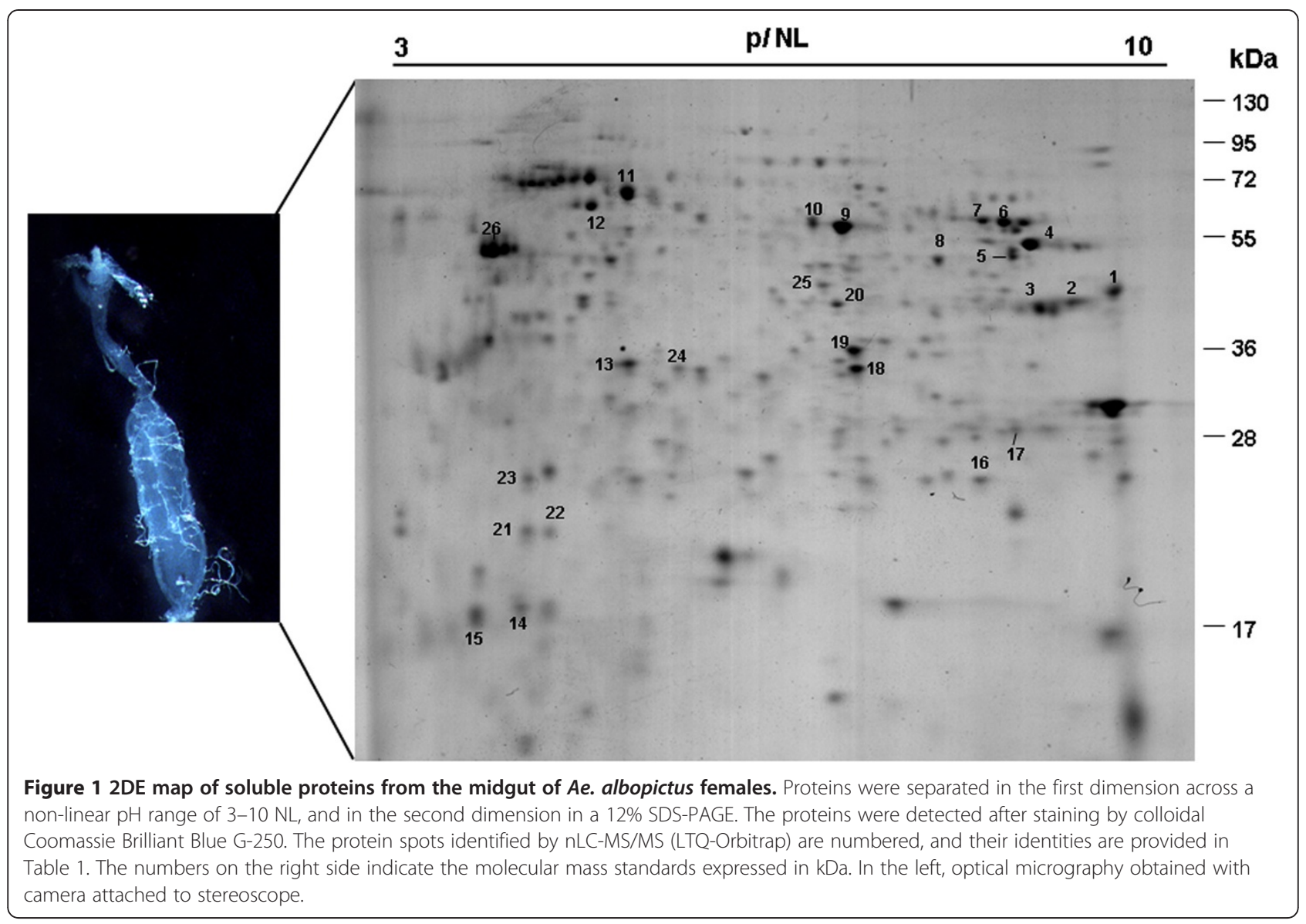

2D map of an Aedes spp. The presence of protein disulfide isomerase, chaperonin-60 and enolase among the most abundant proteins was in good agreement with the midgut proteome analysis of Ae. aegypti [14,23]. The congruence between the theoretical molecular mass and experimental MW of the identified proteins (Table 1) indicates that primarily full-length proteins were present in the midgut extract.

\section{Biological processes of the identified proteins and potential functional associations}

Ae. albopictus proteins could be classified in 15 categories according to GO annotation of biological processes at the VectorBaseDB (Table 2, Figure 2). The most abundant groups correspond to proteins involved in amino acid metabolism, proteins with unknown biological process and proteins involved in the cell redox homeostasis (Figure 2). Other proteins were clustered into categories of those participating in the response to oxidative stress, (catalase and superoxide dismutase); phosphorylation (pyridoxine kinase); proteolysis (leucine aminopeptidase) and iron transport (transferrin), among others.
Further information about the role of Ae. albopictus midgut proteins was obtained analyzing the potential functional associations among the identified proteins using the STRING 9.0 server, a database that provides information about known and predicted protein-protein interactions. This analysis revealed 5 consistent groups of functional associations (Figure 3). The first one is composed of proteins involved in glycolysis (pyruvate kinase, enolase, fructose-bisphosphate aldolase), protein folding (chaperonin-60, ch60), electron carrier (electron transport oxidoreductase), and ketone body catabolism (succinylCoA:3-ketoacid-coenzyme A transferase) (Figure 3, green cluster). The second functional association group includes proteins from carbohydrate and amino acid metabolism such as cystathionine beta-lyase, malate dehydrogenase, glutamate dehydrogenase and aspartate aminotransferase (Figure 3, red cluster). The repertoire of amino acid metabolism associated proteins identified in the midgut of the insects could be correlated to several factors: (i) constitutive expression of this group of proteins for the maintenance of basal metabolism, including protein turnover of midgut structural proteins; (ii) early after metamorphosis, females are fertilized and start to suffer changes in their metabolic machinery as preparation for the blood feeding; (iii) as 
Table 1 Proteins automatically identified using the Mascot software

\begin{tabular}{|c|c|c|c|c|c|c|c|c|c|c|}
\hline $\begin{array}{l}\text { Spot } \\
\text { code }\end{array}$ & Protein name & $\begin{array}{r}\text { NCBI accesion } \\
\text { No. }\end{array}$ & $\begin{array}{r}\text { VectorBase } \\
\text { DB No. }\end{array}$ & $\begin{array}{r}\text { Theor/Exp } \\
\text { MW }\end{array}$ & $\begin{array}{r}\text { Theor/Exp } \\
\mathrm{p} /\end{array}$ & $\begin{array}{r}\text { Matching pep./ } \\
\text { Pep. identified } \\
\text { by MS/MS }\end{array}$ & Peptide sequence & $\begin{array}{r}\text { Error } \pm \\
\text { ppm }\end{array}$ & $\begin{array}{r}\text { Protein } \\
\text { score }\end{array}$ & $\begin{array}{r}\text { Ion } \\
\text { score }\end{array}$ \\
\hline \multirow[t]{15}{*}{1} & aspartate & gi|157128621 & AAEL002399 & $47.6 / 45.5$ & $9.1 / 8.2$ & $14(7)$ & K.KINLGVGAYR.D & 4 & & 60 \\
\hline & & & & & & & K.INLGVGAYR.D & 4 & & 48 \\
\hline & & & & & & & K.EYSPISGTAEFCK.H & 4 & & 50 \\
\hline & & & & & & & R.VGGAFLNGFFPGTK.D & 4 & & 77 \\
\hline & & & & & & & K.DIYLPTPSWGNHGPIFR.H & 5 & & 16 \\
\hline & & & & & & & R.YYDPSTCGFDFK.G & 4 & & 62 \\
\hline & & & & & & & K.GALEDLSK.I & 4 & & 52 \\
\hline & & & & & & & K.DGHQIALAQSFAK.N & 4 & & 49 \\
\hline & & & & & & & R.AGAFSLICSDKEEAAR.T & 4 & & 78 \\
\hline & & & & & & & K.ILIRPMYSNPPIHGAR.L & 4 & & 42 \\
\hline & & & & & & & R.LVSEILGDANLK.Q & 4 & & 38 \\
\hline & & & & & & & K.LMADR.I & 2 & & 23 \\
\hline & & & & & & & R.ISMAGVTTK.N & 4 & & 44 \\
\hline & & & & & & & K.NVDYLAEAIHAVTK. & 4 & & 80 \\
\hline & & & & & & & K.NVDYLAEAIHAVTK. & 5 & & 45 \\
\hline \multirow[t]{4}{*}{1} & ATP synthase alpha & gi|157131648 & AAEL012175 & $59.5 / 45.5$ & $9.0 / 8.2$ & $4(3)$ & R.WDALGNAIDGK.G & 4 & 81 & 34 \\
\hline & & & & & & & K.TALAIDTIINQQR.F & 4 & & 57 \\
\hline & & & & & & & K.HALIIYDDLSK.Q & 5 & & 66 \\
\hline & & & & & & & K.ALLSQIATDGK.I & 4 & & 6 \\
\hline \multirow[t]{7}{*}{2} & $d-3-$ & gi|157109536 & AAEL005336 & $35.7 / 32.8$ & $8.0 / 7.8$ & $12(6)$ & K.SVLVCDAVDNSCVK.L & 1 & 237 & 44 \\
\hline & & & & & & & K.LLQDHGIK.V & 1 & & 19 \\
\hline & & & & & & & K.LLQDHGIK.V & 3 & & 34 \\
\hline & & & & & & & K.GYDAVIVR.S & 1 & & 33 \\
\hline & & & & & & & K.ITAEILDAGSGK.L & 3 & & 98 \\
\hline & & & & & & & R.AGAGVDNIDIVAATR.N & 2 & & 50 \\
\hline & & & & & & & R.KLYSGSELYGK.T & 3 & & 88 \\
\hline
\end{tabular}




\begin{tabular}{|c|}
\hline K.LYSGSELYGK.T \\
\hline R.MNAFGMR.V \\
\hline K.WATPHLGASTSEAQVR.V \\
\hline R.VAVEVAEQFIALTGK.S \\
\hline R.VAVEVAEQFIALTGK.S \\
\hline K.DVQEELAR.I \\
\hline K.GILAADESTATCGK.R \\
\hline R.FADIGVENNEDNR.R \\
\hline K.NTPSYQAILENANVLAR.Y \\
\hline K.VTETVLAAVYK.A \\
\hline K.DVQEELAR.I \\
\hline K.GILAADESTATCGK.R \\
\hline R.FADIGVENNEDNR.R \\
\hline R.QLLFTADDR.L \\
\hline R.LQENISGVILFHETLYQK.A \\
\hline K.ADDGTPLAAMLK.K \\
\hline K.GWDLMGSEGECTTQGLDDLGAR.C \\
\hline K.GWDLMGSEGECTTQGLDDLGAR.C \\
\hline R.CAQYK.K \\
\hline K.KDGCDFAK.W \\
\hline K.NTPSYQAILENANVLAR.Y \\
\hline K.NTPSYQAILENANVLAR.Y \\
\hline R.IVPIVEPEILPDGDHDLER.C \\
\hline R.IVPIVEPEILPDGDHDLER.C \\
\hline K.VTETVLAAVYK.A \\
\hline K.ALNDHHVFLEGTLLKPNMVTAGQSCAK.K \\
\hline K.KPSAQEIALATVLALR.R \\
\hline K.KPSAQEIALATVLALR.R \\
\hline K.AAQDELIK.R \\
\hline
\end{tabular}

$\begin{array}{rrr}2 & 68 \\ 4 & 32 \\ 2 & 60 \\ 3 & & 29 \\ 4 & & 121 \\ 2 & 50 & 37\end{array}$


Table 1 Proteins automatically identified using the Mascot software (Continued)

phosphoglycerate
dehydrogenase

[Aedes aegyptic

AAEL005336

$35.7 / 32.8$

$8.0 / 7.5$

2(2)

K.SVLVCDAVDNSCVK.L

Structure Of Aedes

gi|116667854

AAEL000640

$43.4 / 32.8$

$7.1 / 7.5$

1(1)

R.AGAGVDNIDIVAATR.N

K.LLMGPGPSNAPQR.V

Glyoxylate

Aminotransferase

$4 \quad$ ATP synthase alpha

subunit

gi|157131648

AAEL012175

$59.5 / 53.1$

$9.0 / 7.4$

18(7)

R.VLSIGDGIAR.V

mitochondrial [Aedes

aegypti]

\begin{tabular}{ccc} 
R.VLSIGDGIAR.V & 3 & 68 \\
K.NIQADEMVEFSSGLK.G & 5 & 25 \\
K.NIQADEMVEFSSGLK.G & 0 & 18 \\
K.NIQADEMVEFSSGLK.G & 1 & 37 \\
K.NIQADEMVEFSSGLK.G & 3 & 101 \\
K.APGIIPR.V & 2 & 41 \\
R.EPMQTGIK.A & 3 & 28 \\
K.AVDSLVPIGR.G & 3 & 57 \\
R.ELIIGDR.Q & 3 & 38 \\
K.TALAIDTIINQQR.F & 2 & 98 \\
K.RSTVAQIVK.R & 1 & 38 \\
K.HALIIYDDLSK.Q & 1 & 21 \\
R.EAYPGDVFYLHSR.L & 3 & 89 \\
K.GIRPAINVGLSVSR.V & 2 & 22 \\
K.LELAQYR.E & 1 & 40 \\
R.LTELLK.Q & 1 & 25 \\
K.ITAFER.E & 2 & 31 \\
R.ILVINPGNPTGQVLSR.D & 3 & 49 \\
R.NIQADEMVEFSSGLK.G & & 49 \\
K.TILPQPAK.L & 3 & 224 \\
\hline
\end{tabular}

$4 \quad$ ATP synthase alpha 


\section{KGG}

K.GMALNLEPDNVGWVFGNDK.L

K.GMALNLEPDNVGWWFGNDK.L

K.GMALNLEPDNVGWWFGNDK.L

K.GMALNLEPDNVGWVFGNDK.L

R.EVAAFAQFGSDLDAATQQLLNR.G

R.EVAAFAQFGSDLDAATQQLLNR.G

R.LQENISGVILFHETLYQK.A

K.GWDLMGSEGECTTQGLDDLGAR.C K.GWDLMGSEGECTTQGLDDLGAR.C

R.IVPIVEPEILPDGDHDLER.C

K.VTETVLAAVYK.A

K.KTPLAVR.F

R.FSTVGGESGSADTAR.D

K.FYTDDGWWLLVGNTPIFFIR.D

R.DPILFPSFIHTQK.R

R.FMNGYGSHTFK.L

R.FMNGYGSHTFK.L

R.FMNGYGSHTFK.L

K.LVNADGKPVYCK.F

K.RADELAGADPDYSIR.D

K.RADELAGADPDYSIR.D

R.ADELAGADPDYSIR.D

K.GEYPSWTLK.I

K.IQVMTFEQAEK.L

K.IWPQAEFPLIPVGR.M

K.NYFAEVEQIAFDPSSMVPGIEASPDK.M

R.LFAYTDTHR.H

R.LGANYTQLPVNCPYR.V

K.HSVSGDIDR.F

K.HSVSGDIDRFESGDEENFAQASVFYR.R

R.FESGDEENFAQASVFYR.R
$-5$

83

24

41

86

149

58

$230 \quad 47$

3
4

4
4

4

3

$484 \quad 30$

110

100

55

26

29

27

37

36

61

87

2

83

64

75

70

89

48

33

74 
Table 1 Proteins automatically identified using the Mascot software (Continued)

R.MISNLVNHMSNASPFIQER.A

K.NFAEVDADFGR.Q

R.NPAENQLNLFK.E

K.KTPLAVR.F

R.FSTVGGESGSADTAR.D

K.FYTDDGWWLLVGNNTPIFFIR.D

R.DPILFPSFIHTQK.R

R.FMNGYGSHTFK.L

R.FMNGYGSHTFK.L

R.FMNGYGSHTFK.L

K.NIQADEMVEFSSGLK.G

\section{K.TALAIDTIINQQR.F}

R.EVAAFAQFGSDLDAATQQLLNR.G

R.EVAAFAQFGSDLDAATQQLLNR.G

K.KTPLAVR.F

R.FSTVGGESGSADTAR.D

K.FYTDDGWWLVGNNTPIFFIR.D

R.DPILFPSFIHTQK.R

R.FMNGYGSHTFK.L

R.FMNGYGSHTFK.L

R.FMNGYGSHTFK.L

K.LVNADGKPVYCK.F

K.RADELAGADPDYSIR.D

K.RADELAGADPDYSIR.D

R.ADELAGADPDYSIR.D

K.GEYPSWTLK.I

K.IQVMTFEQAEK.L

K.IWPQAEFPLIPVGR.M

K.NYFAEVEQIAFDPSSMVPGIEASPDK.M

R.LFAYTDTHR.H 
6 catalase [Aedes aegypti]

gi|157135803

AAEL013407

$57.1 / 58.4$

$7.7 / 7.1$

$8(4)$

ATP synthase alpha

subunit

mitochondrial [Aedes

aegypti]

6 glutamate

dehydrogenase

[Aedes aegypti]

gi|157126232

AAEL010464

$61.6 / 58.4$

$8.3 / 7.1$

5(2)

catalase [Aedes

aegypti]
R.LGANYTQLPVNCPYR.V K.HSVSGDIDR.F

K.HSVSGDIDRFESGDEENFAQASVFYR.R

R.FESGDEENFAQASVFYR.R

R.MISNLVNHMSNASPFIQER.A

K.NFAEVDADFGR.Q

R.NPAENQLNLFK.E

K.KTPLAVR.F

R.FSTVGGESGSADTAR.D

K.FYTDDGWWLLVGNTPIFFIR.D

R.DPILFPSFIHTQK.R

R.FMNGYGSHTFK.L

R.FMNGYGSHTFK.L

R.FMNGYGSHTFK.L

K.NIQADEMVEFSSGLK.G

K.TALAIDTIINQQR.F

R.EVAAFAQFGSDLDAATQQLLNR.G

R.EVAAFAQFGSDLDAATQQLLNR.G

R.DSGDYEMITGYR.A

R.GVFHGLDNFIK.E

R.AGATCIGIIEHDGSIFNPQGIDPK.A

K.DIVHSGLDYTMER.S

K.YNLGLDLR.S

K.KTPLAVR.F

R.FSTVGGESGSADTAR.D

K.FYTDDGWWDLVGNNTPIFFIR.D

K.FYTDDGWWLVGNNTPIFFIR.D

R.DPILFPSFIHTQK.R

R.DPILFPSFIHTQK.R 

aegypti]
R.FMNGYGSHTFK.L

R.FMNGYGSHTFK.L

K.LVNADGKPVYCK.F

K.RADELAGADPDYSIR.D

K.RADELAGADPDYSIR.D

R.ADELAGADPDYSIR.D

K.IQVMTFEQAEK.L

K.IWPQAEFPLIPVGR.M

K.NYFAEVEQIAFDPSSMVPGIEASPDK.M

$$
\text { R.LFAYTDTHR.H }
$$

R.LFAYTDTHR.H

R.LGANYTQLPVNCPYR.V

$$
\text { K.HSVSGDIDR.F }
$$

R.FESGDEENFAQASVFYR.R

R.MISNLVNHMSNASPFIQER.A

K.NFAEVDADFGR.Q

R.NPAENQLNLFK.E

K.KTPLAVR.F

R.FSTVGGESGSADTAR.D

K.FYTDDGWWDLVGNNTPIFFIR.D

K.FYTDDGWWLVGNNTPIFFIR.D

R.DPILFPSFIHTQK.R

R.DPILFPSFIHTQK.R

R.FMNGYGSHTFK.L

R.FMNGYGSHTFK.L

R.LSGIICTIGPASVAPEMLEK.M

K.MMATGMNIAR.L

K.IENQQGMQNLDAIIAASDGIMVAR.G R.AGKPVICATQMLESMIK.K

R.AEISDVANAIIDGADCVMLSGETAK.G R.AEISDVANAIIDGADCVMLSGETAK.G 


$$
\text { aegypti] }
$$

K.LMHQASLLGEAIHDAQPYGWK.F

K.LMHQASLLGEAIHDAQPYGWK.F

$$
\text { K.VEYVNGLGYFK.D }
$$

K.DAHNWAVMK.N

$$
\text { K.DAHNWAVMK.N }
$$

R.GFDQQMATMVGDAMVEK.G

R.GFDQQMATMVGDAMVEK.G

K.LDQAGWTAEGGK.S

K.AVALLEGDQK.V

K.NTVGIHPTVAEEFTR.L

K.SSGLDPTPATCCS.- 
10 thioredoxin reductase [Aedes aegypti]

10 dihydrolipoamide dehydrogenase [Aedes aegypti]

11 transferrin [Aedes aegypti] gi|157132842

AAEL002886

$54.4 / 58.4$

$62 / 60$

$5(5)$

AAEL006928

$54.1 / 58.4$

$6.3 / 6.0$

gi|157129886

AAEL011641

$87.1 / 66.9$

$4.9 / 5.4$

16(11)
$61.1 / 61.8$
$5.4 / 5.3$
K.ALLNNSHYYHMAHSGDLASR.G

K.MADGSEEWNAK.N

K.MADGSEEWNAK.N

R.RPYTEGLGLENVGIVK.D

R.VCHAHPTCAEALR.E

R.VCHAHPTCAEALR.E

K.TLWGAGYIGLECAGFLK.

RSDDGTEGSDYVTVLFAIGRT

K.SDKLDVDSFETTNVPNIFAVGDVLYK.R

K.LDVDSFETTNVPNIFAVGDVLYK.R

K.VLGLHFLGPVAGEVIQGFAAALKS

R.LGAEVTAIEFLSSIGGAGIDQEVSK.S

R.VPVNSVFOTIVPSIYAIGDCIHGPMLAHK.A

R.VLGVHIIGPAAGELINEAVLAMEYGASAEDVAR.V

$$
\text { K.FSEQCLQLQR.G }
$$

\section{R.GNPEWCVTVQDSIECAQR.I}

$$
\text { R.EWDFR.S }
$$

R.SWWSSQHQGGVDGLR.N

K.KFCHPGLHYGR.Q

K.KFCHPGLHYGR.Q

K.FCHPGLHYGR.Q

K.FCHPGLHYGR.Q

R.QLPIPSDLCQTTSR.W

R.WCTTSPEEK.D

R.TAALTTGIFPTIECVDPTTSR.M

R.ADFTGIDSNFGYLAR.H

K.YSSWVLVR.A

R.FENLR.N

R.GIFDQHECDYGR.L

R.GIFDQHECDYGR.L

K.LVQDVANNTNEEAGDGTTTATVLAR.A 
Table 1 Proteins automatically identified using the Mascot software (Continued)

\begin{tabular}{|c|c|c|c|c|c|c|c|c|c|c|}
\hline & $\begin{array}{l}\text { chaperonin-60kD, } \\
\text { ch60 [Aedes aegypti] }\end{array}$ & & & & & & & & & \\
\hline & & & & & & & K.LVQDVANNTNEEAGDGTTTATVLAR.A & 0 & & 48 \\
\hline & & & & & & & K.GANPVEIR.R & 0 & & 24 \\
\hline & & & & & & & R.RGVMLAVDAVK.D & 1 & & 40 \\
\hline & & & & & & & K.APGFGDNR.K & 2 & & 34 \\
\hline & & & & & & & K.LEDVQMSDLGQVGEITITK.D & -1 & & 125 \\
\hline & & & & & & & K.IGGSSEVEVNEK.K & 0 & & 85 \\
\hline & & & & & & & K.TLENLK.G & 1 & & 31 \\
\hline & & & & & & & R.ALHQPCTQIAK.N & 1 & & 43 \\
\hline & & & & & & & K.NAGVDGSWVAK.V & -1 & & 79 \\
\hline \multirow[t]{16}{*}{12} & $\begin{array}{l}\text { chaperonin-60kD, } \\
\text { ch60 [Aedes aegypti] }\end{array}$ & gi|157129785 & AAEL011584 & $61.1 / 61.8$ & $5.4 / 5.3$ & 16(9) & R.ALMLQGVDVLADAVAVTMGPK.G & 0 & 431 & 76 \\
\hline & & & & & & & R.ALMLQGVDVLADAVAVTMGPK.G & 2 & & 8 \\
\hline & & & & & & & R.ALMLQGVDVLADAVAVTMGPK.G & 2 & & 30 \\
\hline & & & & & & & R.ALMLQGVDVLADAVAVTMGPK.G & 4 & & 34 \\
\hline & & & & & & & R.ALMLQGVDVLADAVAVTMGPK.G & -4 & & 77 \\
\hline & & & & & & & R.ALMLQGVDVLADAVAVTMGPK.G & 4 & & 103 \\
\hline & & & & & & & K.TLHDELEIIEGMK.F & -1 & & 21 \\
\hline & & & & & & & R.KPLVIIAEDVDGEALSTLWNR.L & -6 & & 43 \\
\hline & & & & & & & R.KPLVIIAEDVDGEALSTLWNR.L & -1 & & 40 \\
\hline & & & & & & & R.KPLVIIAEDVDGEALSTLWNR.L & 2 & & 7 \\
\hline & & & & & & & R.KPLVIIAEDVDGEALSTLWNR.L & 3 & & 111 \\
\hline & & & & & & & K.STLSDMAISTGGIVFGDDANLVK.L & 2 & & 99 \\
\hline & & & & & & & K.STLSDMAISTGGIVFGDDANLVK.L & 5 & & 52 \\
\hline & & & & & & & K.STLSDMAISTGGIVFGDDANLVK.L & 1 & & 104 \\
\hline & & & & & & & K.STLSDMAISTGGIVFGDDANLVK.L & 2 & & 47 \\
\hline & & & & & & & K.LEDVQMSDLGQVGEITITK.D & 1 & & 114 \\
\hline 12 & $\begin{array}{l}\text { dihydrolipoamide } \\
\text { dehydrogenase } \\
\text { [Aedes aegypti] }\end{array}$ & gi|157114623 & AAEL006928 & $54.1 / 61.8$ & $6.3 / 5.3$ & $1(1)$ & R.MGLIGAGVIGLELGSWWGR.L & 2 & 103 & 103 \\
\hline \multirow[t]{2}{*}{13} & $\begin{array}{l}\text { anterior fat body } \\
\text { protein [Aedes } \\
\text { aegypti] }\end{array}$ & gi|157110227 & AAEL000757 & $39.7 / 34.4$ & $6.1 / 5.4$ & $2(1)$ & K.FVEQFDK.V & 3 & 73 & 44 \\
\hline & & & & & & & K.FYYADTGAYDVK.V & 3 & & 73 \\
\hline
\end{tabular}


Table 1 Proteins automatically identified using the Mascot software (Continued)

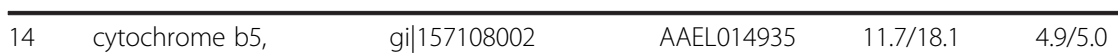

$7(4)$

K.TFSLAEIK.A

15605 acidic ribosomal

gi|157105859

AAEL014583

$4.5 / 4.8$

K.SDRPSLTAAK.I

protein P2 [Aedes

aegypti]

15 hypothetical protein

AaeL_AAEL005270

gi|157109287

AAEL005270

$15.5 / 17.0$

$4.8 / 4.8$

K.DATEAFEDVGHSTDAR.E

K.DATEAFEDVGHSTDAR.E

K.VGELIESER.K

R.KQVPVK.K

K.KEPDWSTEQK.D

K.EPDWSTEQK.D

K.SDLTEFVSQELTK.S

$66-66$

K.ILSSVGIEADSTR.V

\section{K.SVEELIASGR.E}

K.LSSMPAGGAAPAAGAGAAAGGAAAAPAEEK.K

K.WWWTNAHGPYPPNMVSGGQDSDGALLYVGR.A

(1)

K.ELIWDSATGGNIPPDAWGGNTADGEPLYIGR.A

R.AYHEGSQTIGK.V

R.AYHEGSQTIGK.V

R.SHGCCYIPYGGAEVSVPTYDVLCER.-

$$
\text { K.NTSSSAFR.K }
$$

K.WLQNAPLLCK.N

kd subunit (P16-arc)

gi|157120584

AAEL009059

$16.9 / 17.0$

$4.7 / 4.8$

2(1)

[Aedes aegypti]

16 superoxide

dismutase, $\mathrm{Mn}$

gi|157107594

AAEL004823

$24.6 / 25.8$

$8.3 / 6.9$

5(2)

K.HTLPDLPYDFGALEPVICR.E

51

[Aedes aegypti]

R.EIMEVHHQK.H

K.HHNAYVTNLNAAEEQLAEAVAK.K

R.SDPSAELKK.L 
Table 1 Proteins automatically identified using the Mascot software (Continued)

16

\begin{tabular}{|c|c|c|c|c|}
\hline AAEL011268 & $25.1 / 25.8$ & $5.8 / 6.9$ & $2(1)$ & R. \\
\hline $\begin{array}{l}\text { cyclohex-1-ene-1- } \\
\text { carboxyl-CoA } \\
\text { hydratase, putative } \\
\text { [Aedes aegypti] }\end{array}$ & gi|157104013 & AAEL003993 & $31.9 / 29.6$ & $8.7 / 7.3$ \\
\hline $\begin{array}{l}\text { 3-hydroxyisobutyrate } \\
\text { dehydrogenase } \\
\text { [Aedes aegypti] }\end{array}$ & gi|157137993 & AAEL013904 & $34.1 / 29.6$ & $8.7 / 7.3$ \\
\hline $\begin{array}{l}\text { pyridoxine kinase } \\
\text { [Aedes aegypti] }\end{array}$ & gi|157123752 & AAEL009601 & $34.0 / 26.9$ & $6.5 / 6.3$ \\
\hline $\begin{array}{l}\text { malate } \\
\text { dehydrogenase } \\
\text { [Aedes aegypti] }\end{array}$ & gi|157116681 & $\begin{array}{r}\text { gi|157116681 } \\
\text { AAEL007707 }\end{array}$ & $36.4 / 25.8$ & $6.0 / 6.3$ \\
\hline
\end{tabular}

K.NLRPNYVDAIWDWNWK.D

phosphatidylethanolaminebinding protein [Aedes aegypti]

$$
\begin{aligned}
& \text { IAFVGSGPPQGSGLHR.Y } \\
& \text { K.YNLGELVAGNFYR.A } \\
& \text { K.NVALITLNRPK.A }
\end{aligned}
$$

$85 \quad 27$

$142 \quad 58$

K.CITGNFLNNWTSVAK.A

K.ISTFSPLIVQLCK.E

K.EAVNTAYETTLNEGLK.F

K.DRLEGMTAFVEK.R

K.GAVTYDNVSELAK.A

K.VFSDIINASTGR.S

R.VLSIQSHWHGYVGNK.S

R.VLSIQSHWHGYVGNK.S

K.FDMCATLER.T Oxidation (M)

$$
\text { K.GDVFGPNQR.L }
$$

K.VLWGNPANTNALVCSHYAPSIPK.E

$$
\text { K.ENFTAMTR.L }
$$

K.ENFTAMTR.L Oxidation (M)

K.DGEYVSMGWSDGSYGTPK.D

K.DGEYVSMGWSDGSYGTPK.D Oxidation (M)

K.IVQGLSVDDFAR.G

K.ELLEEKEEAMSVCASD.-

K.ELLEEKEEAMSVCASD.- Oxidation (M)

$$
\text { R.FADIGVENNEDNR.R }
$$


Table 1 Proteins automatically identified using the Mascot software (Continued)

\begin{tabular}{|c|c|c|c|c|c|c|c|c|c|c|}
\hline & & & & & & & R.IVPIVEPEILPDGDHDLER.C & 3 & & 18 \\
\hline \multirow[t]{11}{*}{20} & \multirow[t]{11}{*}{$\begin{array}{l}\text { cystathionine beta- } \\
\text { lyase [Aedes aegypti] }\end{array}$} & \multirow[t]{11}{*}{ gi|157104405 } & \multirow[t]{11}{*}{ AAEL004059 } & \multirow[t]{11}{*}{$44.3 / 18.1$} & \multirow[t]{11}{*}{$6.0 / 5.1$} & \multirow[t]{11}{*}{$11(7)$} & R.AWPPISMSTTFK.Q & 3 & \multirow[t]{11}{*}{194} & 44 \\
\hline & & & & & & & K.QFGPAQHAGYEYGR.S & 3 & & 21 \\
\hline & & & & & & & K.MNIEVDFVDCTDLAK.V & 5 & & 49 \\
\hline & & & & & & & K.MNIEVDFVDCTDLAK.V Oxidation (M) & 4 & & 83 \\
\hline & & & & & & & K.VEAAVKPNTK.L & -5 & & 48 \\
\hline & & & & & & & K.LFWIETPTNPLLK.V & 5 & & 65 \\
\hline & & & & & & & K.FLQNAAGIVPSPFDCYLVNR.S & 5 & & 66 \\
\hline & & & & & & & K.FLQNAAGIVPSPFDCYLVNR.S & 6 & & 34 \\
\hline & & & & & & & R.VLHPGLPSHPQHELAK.K & 2 & & 29 \\
\hline & & & & & & & R.VLHPGLPSHPQHELAK.K & 3 & & 18 \\
\hline & & & & & & & R.ISVGLEDADDLIVDLK.Q & 6 & & 110 \\
\hline \multirow[t]{3}{*}{20} & \multirow{3}{*}{$\begin{array}{l}\text { hypothetical protein } \\
\text { AaeL_AAELO15064 } \\
\text { [Aedes aegypti] }\end{array}$} & \multirow[t]{3}{*}{ gi|157108923 } & \multirow[t]{3}{*}{ AAEL015064 } & \multirow[t]{3}{*}{ 10.9/18.1 } & \multirow[t]{3}{*}{$5.6 / 5.1$} & \multirow[t]{3}{*}{$3(2)$} & K.GSESEHINLK.V & 2 & \multirow[t]{3}{*}{81} & 52 \\
\hline & & & & & & & R.KLMNAYCDR.A Oxidation (M) & 2 & & 37 \\
\hline & & & & & & & R.KLMNAYCDR.A Oxidation (M) & -6 & & 77 \\
\hline \multirow[t]{3}{*}{21} & \multirow{3}{*}{$\begin{array}{l}\text { mitochondrial F0 ATP } \\
\text { synthase D chain, } \\
\text { putative [Aedes } \\
\text { aegypti] }\end{array}$} & \multirow[t]{3}{*}{ gi|157106010 } & \multirow[t]{3}{*}{ AAEL004423 } & \multirow[t]{3}{*}{$19.6 / 22.5$} & \multirow[t]{3}{*}{$5.2 / 5.1$} & \multirow[t]{3}{*}{$3(3)$} & R.IAQSSVNWAALAER.V & 3 & \multirow[t]{3}{*}{133} & 92 \\
\hline & & & & & & & R.IADYQSQIAALK.A & 3 & & 90 \\
\hline & & & & & & & K.ALLPFDQMTMEDYR.D 2 Oxidation (M) & 3 & & 48 \\
\hline 21 & $\begin{array}{l}\text { cystathionine beta- } \\
\text { lyase [Aedes aegypti] }\end{array}$ & gi|157104405 & AAEL004059 & $44.3 / 22.5$ & $6.02 / 5.1$ & $1(1)$ & R.ISVGLEDADDLIVDLK.Q & 6 & 118 & 118 \\
\hline \multirow[t]{4}{*}{22} & \multirow[t]{4}{*}{$\begin{array}{l}\text { lactoylglutathione } \\
\text { lyase [Aedes aegypti] }\end{array}$} & \multirow[t]{4}{*}{ gi|157104950 } & \multirow[t]{4}{*}{ AAEL014393 } & \multirow[t]{4}{*}{$20.7 / 22.5$} & \multirow[t]{4}{*}{$5.3 / 5.1$} & $4(1)$ & K.DFLFQQTMYR.I & 2 & 90 & 32 \\
\hline & & & & & & & K.ATLELTHNWGTESDPDQK.Y & 3 & & 35 \\
\hline & & & & & & & R.GYGHIGIMVPDVEK.A Oxidation (M) & 1 & & 37 \\
\hline & & & & & & & K.DPDGYWIEIFNASK.V & 6 & & 90 \\
\hline 23 & glutathione s- & gi|157130284 & AAEL011741 & $27.0 / 25.8$ & $5.2 / 5.1$ & $7(6)$ & R.FLLSYGNLPFDDIR.I & 5 & 179 & 90 \\
\hline & & & & & & & R.EEWPALKPTMPMGQMPVLSVDGK.K & 4 & & 54 \\
\hline & & & & & & & K.KVHQSVAMSR.Y Oxidation (M) & 3 & & 19 \\
\hline & & & & & & & K.QVGLAGADDWENLMIDTWDTINDFR.L & 8 & & 64 \\
\hline
\end{tabular}


Table 1 Proteins automatically identified using the Mascot software (Continued)

23 rho guanine dissociation factor [Aedes aegypti]

24 anterior fat body protein [Aedes aegypti]

25 aliphatic nitrilase putative [Aedes aegypti]

26 ATP synthase beta subunit [Aedes aegypti]

$\begin{array}{llll}\text { gi|157134192 } & \text { AAEL012996 } & 23.0 / 25.8 & 5.0 / 5 . \\ \text { gi|157110227 } & \text { AAEL000757 } & 39.7 / 35.2 & \\ & & & \\ & & & \\ & & & \\ & & & \end{array}$

gi|157125650

AAEL010284

$6.0 / 5.9$

6(2)

gi|157132308

AAEL002827

$53.8 / 53.1$

$5.0 / 4.9$

34(27)
K.IAWSYEPDDDVKEK.K

K.LVTLNSEVIPFYLEK.L

R.WDNVTSIDSIK.A

K.EALLGEAQSEK

K.FVEQFDK.V

K.FYYADTGAYDVK.V

R.HIPPEELR.E

R.HIPPEELR.E

K.QYNMVIISPILER.D Oxidation (M)

R.KNHIPR.V

K.NHIPR.V

K.DFWGFPMTQR.L Oxidation (M)

R.LVLEVAQHLGENTVRT

R.TIAMDGTEGLVR.G

R.TIAMDGTEGLVR.G Oxidation (M)

R.VLDTGSPIR.I

R.IPVGAETLGR.I

R.IINVIGEPIDER.G

R.GPIETNLSAPIHAEAPEFIDMSVEQEILVTGIK.V

R.GPIETNLSAPIHAEAPEFIDMSVEQEILVTGIK.V Oxidation (M)

K.WDLLAPYAK.G

K.IGLFGGAGVGK.T

K.TVLIMELINNVAK.A

R.EGNDLYNEMIEGGVISLK.D

R.EGNDLYNEMIEGGVISLK.D

R.EGNDLYNEMIEGGVISLK.D Oxidation (M)

K.VALVYGQMNEPPGAR.A Oxidation (M)

R.VALTGLTVAEYFR.D 


\begin{tabular}{|c|c|c|c|c|c|c|c|c|c|}
\hline & & & & & & & R.DQEGQDVLLFIDNIFR.F & 6 & $\overline{60}$ \\
\hline & & & & & & & R.FTQAGSEVSALLGR.I & 3 & 90 \\
\hline & & & & & & & R.IPSAVGYQPTLATDMGSMQER.I & 4 & 73 \\
\hline & & & & & & & R.IPSAVGYQPTLATDMGSMQER.I Oxidation (M) & 3 & 93 \\
\hline & & & & & & & R.IPSAVGYQPTLATDMGSMQER.I Oxidation (M) & 5 & 86 \\
\hline & & & & & & & $\begin{array}{l}\text { R.IPSAVGYQPTLATDMGSMQER.I } 2 \text { Oxidation } \\
\qquad(\mathrm{M})\end{array}$ & 4 & 78 \\
\hline & & & & & & & R.AIAELGIYPAVDPLDSTSR.I & 3 & 30 \\
\hline & & & & & & & R.AIAELGIYPAVDPLDSTSR.I & 5 & 54 \\
\hline & & & & & & & R.IMDPNIIGAEHYNIAR.G Oxidation (M) & 2 & 20 \\
\hline & & & & & & & K.ILQDYK.S & 0 & 35 \\
\hline & & & & & & & K.SLQDIIAILGMDELSEEDK.L Oxidation (M) & 10 & 75 \\
\hline & & & & & & & K.SLQDIIAILGMDELSEEDKLTVAR.A & 6 & 84 \\
\hline & & & & & & & $\begin{array}{l}\text { K.SLQDIIAILGMDELSEEDKLTVAR.A Oxidation } \\
(\mathrm{M})\end{array}$ & 5 & 89 \\
\hline & & & & & & & $\begin{array}{l}\text { K.SLQDIIAILGMDELSEEDKLTVAR.A Oxidation } \\
(\mathrm{M})\end{array}$ & 7 & 67 \\
\hline & & & & & & & R.FLSQPFQVAEVFTGHAGK.L & 3 & 42 \\
\hline & & & & & & & R.FLSQPFQVAEVFTGHAGK.L & 5 & 94 \\
\hline & & & & & & & K.ILNGELDHLPEVAFYMVGPIEEWEK.A & 6 & 55 \\
\hline \multirow[t]{9}{*}{26} & protein disulfide & gi|157107430 & AAEL000641 & $56.2 / 53.1$ & $4.9 / 4.9$ & $9(4)$ & K.EEDGVLVLTK.D & 2 & 11 \\
\hline & & & & & & & K.AVFDGEYTEEALK.K & 3 & 66 \\
\hline & & & & & & & K.AVFDGEYTEEALKK.F & 4 & 62 \\
\hline & & & & & & & K.NHLLFFISK.E & 2 & 32 \\
\hline & & & & & & & K.ILFVTIDADQEDHQR.I & 4 & 75 \\
\hline & & & & & & & K.KDEVPSMR.I & 1 & 29 \\
\hline & & & & & & & K.KDEVPSMR.I Oxidation (M) & 3 & 39 \\
\hline & & & & & & & R.IIHLEEDMAK.Y Oxidation (M & 2 & 22 \\
\hline & & & & & & & K.MDATANELEHTK.I & 0 & 28 \\
\hline
\end{tabular}


Table 2 Biological process categories of the identified proteins

\begin{tabular}{|c|c|}
\hline Categories $^{a}$ & $\begin{array}{l}\text { Number of } \\
\text { identified spots }\end{array}$ \\
\hline Amino acid Metabolism & $\underline{10}$ \\
\hline Aspartate aminotransferase & 1 \\
\hline d-3-phosphoglycerate dehydrogenase & 2 \\
\hline Alanine aminotransferase & 1 \\
\hline Glutamate dehydrogenase & 2 \\
\hline 3-hydroxyisobutyrate dehydrogenase & 1 \\
\hline Cystathionine beta-lyase & 2 \\
\hline $\begin{array}{l}\text { Chain A, Alanine Glyoxylate } \\
\text { aminotransferase }\end{array}$ & 1 \\
\hline Response to oxidative stress & $\underline{\mathbf{5}}$ \\
\hline Catalase & 4 \\
\hline Superoxide dismutase, $\mathrm{Mn}$ & 1 \\
\hline Cell redox homeostasis & $\underline{8}$ \\
\hline Thioredoxin reductase & 3 \\
\hline Protein disulfide isomerase & 1 \\
\hline Dihydrolipoamide dehydrogenase & 4 \\
\hline Glycolysis & $\underline{6}$ \\
\hline Fructose-bisphosphate aldolase & 4 \\
\hline Pyruvate kinase & 1 \\
\hline Enolase & 1 \\
\hline Proteolysis & 1 \\
\hline Leucine aminopeptidase & 1 \\
\hline ATP biosynthetic process & $\underline{6}$ \\
\hline ATP synthase alpha subunit mitochondrial & 4 \\
\hline $\begin{array}{l}\text { Mitochondrial F0 ATP synthase D chain, } \\
\text { putative }\end{array}$ & 1 \\
\hline ATP synthase beta subunit & 1 \\
\hline Electron carrier activity & $\underline{\mathbf{2}}$ \\
\hline Cytochrome b5, putative & 1 \\
\hline Electron transport oxidoreductase & 1 \\
\hline Protein folding/chaperons & $\underline{2}$ \\
\hline Chaperonin-60kD, ch60 & 2 \\
\hline Carbohydrate metabolic process & 1 \\
\hline Malate dehydrogenase & 1 \\
\hline Nitrogen compound metabolic process & 1 \\
\hline Aliphatic nitrilase, putative & 1 \\
\hline $\begin{array}{l}\text { Actin filament polymerization/ } \\
\text { Cytoskeleton associated }\end{array}$ & $\underline{1}$ \\
\hline arp2/3 complex 16 kd subunit (P16-arc) & 1 \\
\hline $\begin{array}{l}\text { Translational elongation / DNA } \\
\text { synthesis }\end{array}$ & $\underline{1}$ \\
\hline 605 acidic ribosomal protein P2 & 1 \\
\hline Ketone body catabolic process & $\underline{1}$ \\
\hline $\begin{array}{l}\text { Succinyl-coa:3-ketoacid-coenzyme a } \\
\text { transferase }\end{array}$ & 1 \\
\hline
\end{tabular}

Table 2 Biological process categories of the identified proteins (Continued)

\begin{tabular}{|c|c|}
\hline Iron ion Transport & $\underline{1}$ \\
\hline Transferrin & 1 \\
\hline Phosphorylation & $\underline{1}$ \\
\hline Pyridoxine kinase & 1 \\
\hline Unknown biological process & $\underline{9}$ \\
\hline Anterior fat body protein & 2 \\
\hline $\begin{array}{l}\text { Conserved hypothetical protein } \\
\text { AaeL_AAEL005270 (MF: transferase activity) }\end{array}$ & 1 \\
\hline $\begin{array}{l}\text { Phosphatidylethanolamine-binding protein } \\
\text { (Immune response) }\end{array}$ & 1 \\
\hline $\begin{array}{l}\text { Cyclohex-1-ene-1-carboxyl-CoA hydratase } \\
\text { (MF: catalytic activity) }\end{array}$ & 1 \\
\hline $\begin{array}{l}\text { Conserved hypothetical protein } \\
\text { AaeL_AAEL015064 (MF: protein binding) }\end{array}$ & 1 \\
\hline $\begin{array}{l}\text { Lactoylglutathione lyase (MF: } \\
\text { Lactoylglutathione lyase activity) }\end{array}$ & 1 \\
\hline $\begin{array}{l}\text { rho guanine dissociation factor (MF: Rho } \\
\text { GDP-dissociation inhibitor activity) }\end{array}$ & 1 \\
\hline $\begin{array}{l}\text { Glutathione s-transferase (MF: protein } \\
\text { binding) }\end{array}$ & 1 \\
\hline
\end{tabular}

midguts used in this study are from 2-5 day old females, they can present with proteins still remaining from the pupa. Such proteins would serve as substrate for metabolic activities detected, and (iv) given that before midgut dissection the microbiota was present in the midguts, bacteria and proteins produced by them could have induced the activation of insect midgut enzymes involved in amino acid metabolism.

In the third functional association network, the alpha and beta subunits of mitochondrial ATP synthase, dihydrolipoamide dehydrogenase and mitochondrial F0 ATP synthase D chain, which are functionally associated for ATP production, demonstrated consistent interactions (Figure 3, brown cluster). In addition, functional associations among these three groups were observed (Figure 3), revealing the complexity of the interactions required for the energetic metabolism of midgut cells.

The clusters indicated in green and brown both interact independently with a fourth group of functional association that includes the enzymes cyclohex-1ene-1-carboxyl-CoA hydratase and 3-hydroxyisobutyrate dehydrogenase (Figure 3, blue cluster). Although the VectorBase DB did not assign the biological process in which the cyclohex-1-ene-1-carboxyl-CoA hydratase participates, the STRING analysis indicates that this enzyme could play a role in the interaction between glycolysis and the mitochondrial ATP production pathways. In our work, the enzymes cyclohex-1-ene-1-carboxyl-CoA hydratase 


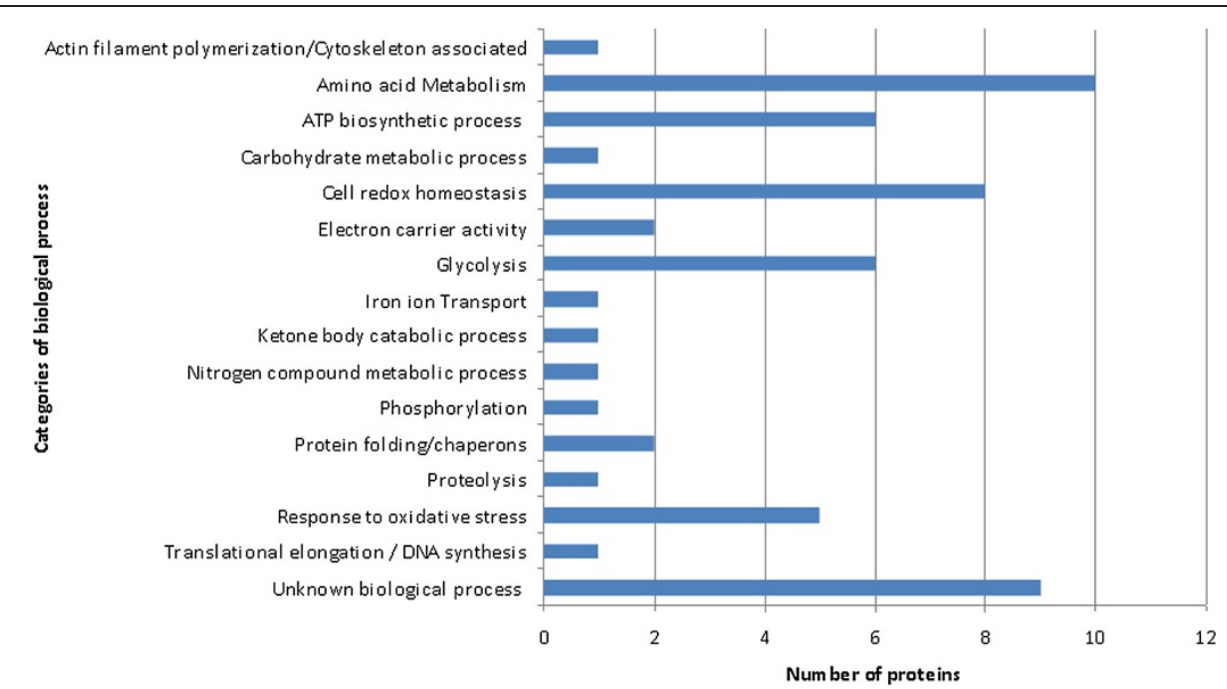

Figure 2 Classification of the identified proteins in biological processes. Categories were obtained from the gene ontology annotations of biological process at VectorBase DB.

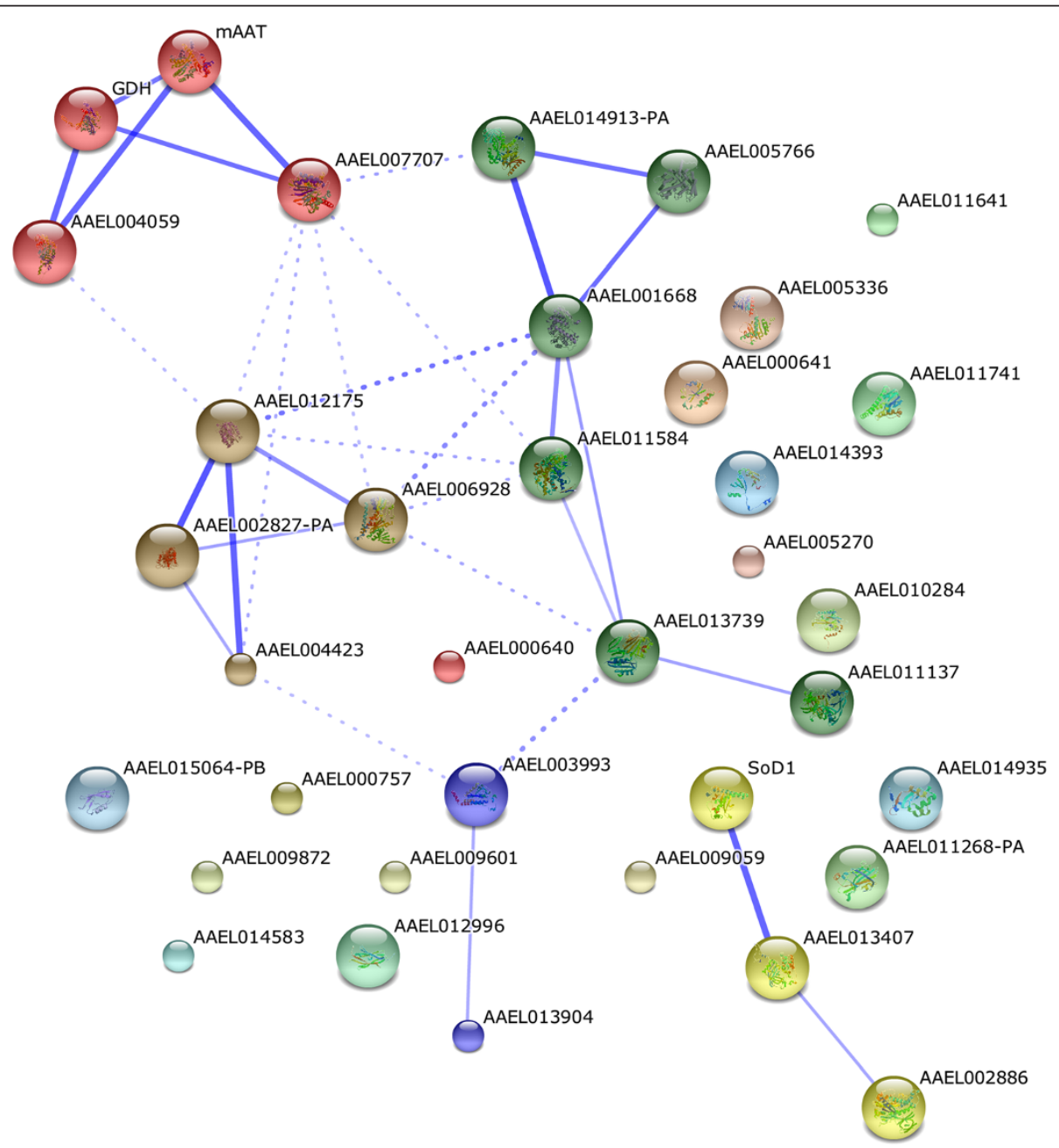

Figure 3 Predicted functional associations among proteins identified in the midgut of sugar-fed Ae. albopictus females. The proteins were analyzed using the STRING database 9.0. The predicted functional interaction networks are shown in the confidence view where the stronger associations are represented by thicker lines. The numbers correspond to the protein accession numbers in the VectorBase database and are described in Table 1. 


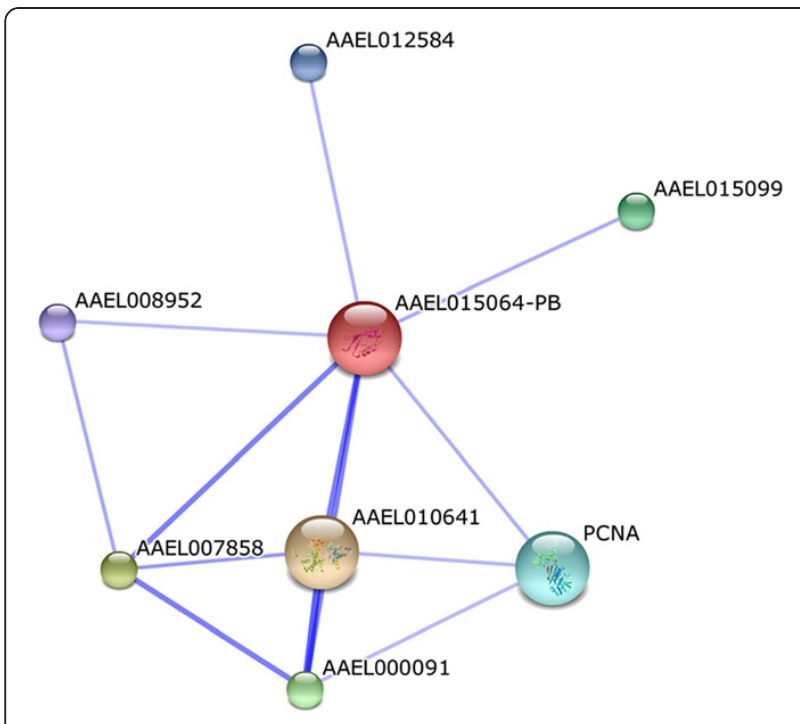

Figure 4 Predicted functional interactions of the conserved hypothetical protein AAEL015064 as displayed by STRING. The partners in this predicted interaction network potentially participate in the SUMO modification of proteins. The predicted functional interaction networks are shown in the confidence view where the stronger associations are represented by thicker lines. AAEL010641: Ubiquitinactivating enzyme E1; AAEL007858: ran GTPase-activating protein; AAEL000091: sumo-1-activating enzyme E1a; AAEL015099: sumo ligase; AAEL008952: sentrin/sumo-specific protease; PCNA: proliferating cell nuclear antigen; AAEL012584: DNA topoisomerase/gyrase.

and 3-hydroxyisobutyrate dehydrogenase were identified in the same spot (spot 18), and these two enzymes have also been identified together in the proteomic analysis of the midgut brush border membrane vesicles of Ae. aegypti [14], supporting the potential functional interaction of

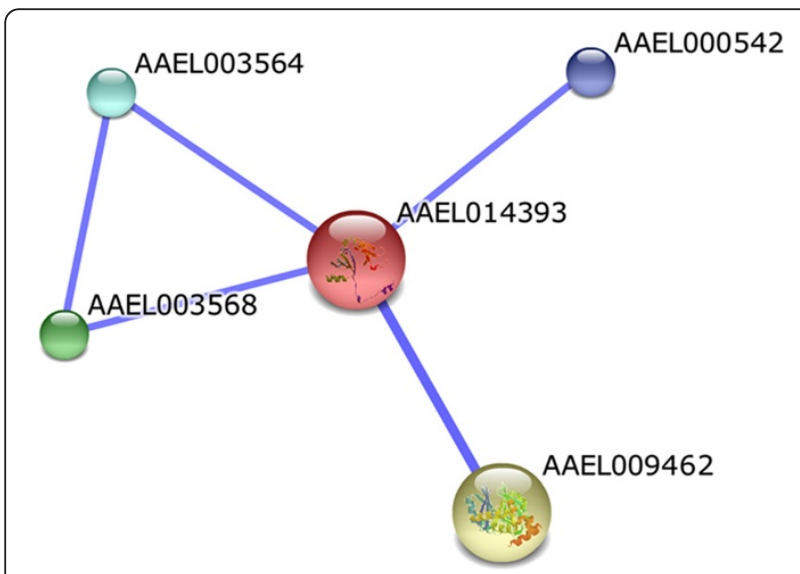

Figure 5 Predicted functional interactions of the enzyme lactoylglutathione lyase (AAEL014393). The proteins associated in this network participate in pyruvate metabolism. The predicted functional interaction networks are shown in the confidence view where the stronger associations are represented by thicker lines. AAEL009462: hydroxyacylglutathione hydrolase; AAEL003568: threonine dehydratase/deaminase; AAEL000542: conserved hypothetical protein.

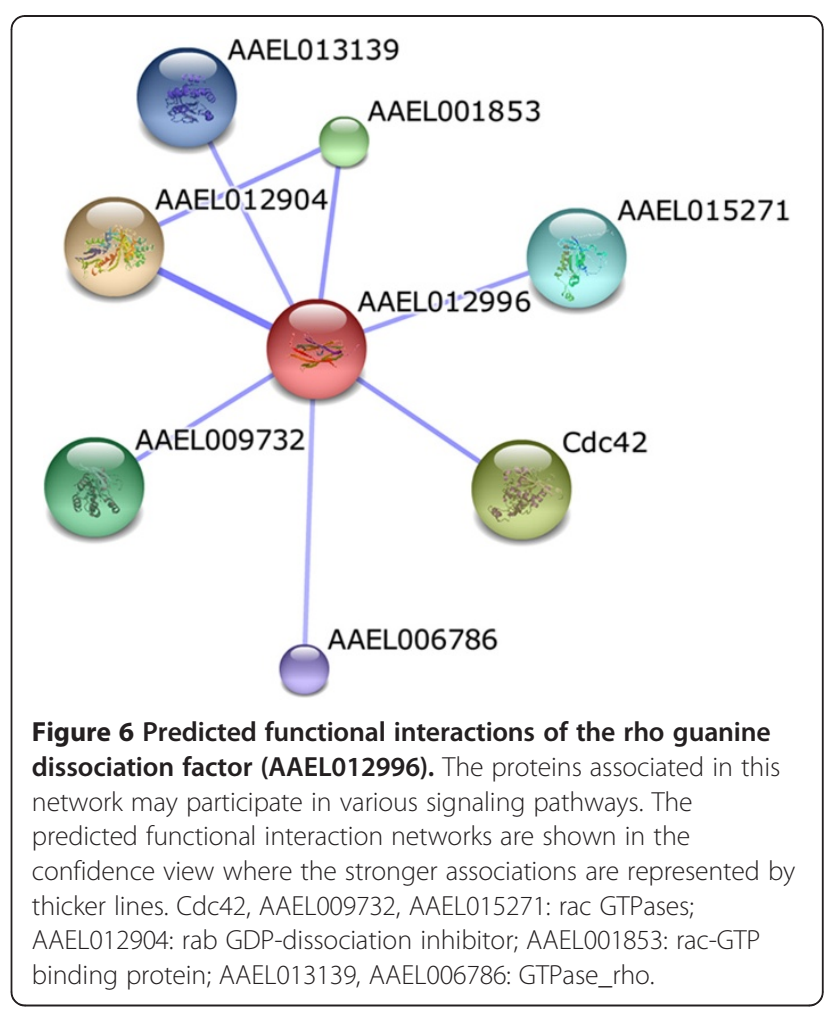

these enzymes. Finally, the enzyme cyclohex-1-ene-1-carboxyl-CoA hydratase has been recently proposed as part of the lipid metabolism pathway in Ae. albopictus [24].

The fifth network involves the functional interaction of superoxide dismutase, catalase and thioredoxin reductase, which interact in the detoxification of free radicals (Figure 3, yellow cluster). These enzymes play a key role in detoxification during carbohydrate meals, and it is expected that female midgut constitutively exhibits a substantial repertoire of these enzymes to deal with the intense oxidative stress induced during the digestion and absorption of a blood meal. In fact, it has been demonstrated that the expression of the genes coding for thioredoxin reductase and catalase in Ae. aegypti increase after blood feeding [25]. In addition, the expression of thioredoxin reductase and catalase in Chironomus riparius during stress by environmental pollutants, such as cadmium chloride, has been proposed as a biomarker of exposition to such contaminants [26,27]. All the other proteins identified in the 2D map appeared as isolated components in the functional association network (Figure 3).

The proteins classified under the "unknown biological process" category were individually submitted to functional association analysis in order to obtain insight into their potential function. No predicted associations were found for AAEL000757, AAEL005270, AAEL011268 and AAEL011741. On the other hand, for the conserved hypo- 
thetical protein AAEL015064, STRING predicted confident association with proteins involved in the potential SUMO modification of proteins, such as ubiquitinactivating enzyme E1 (AAEL010641), ran GTPase-activating protein (AAEL007858), sumo-1-activating enzyme E1a (AAEL000091), sumo ligase (AAEL015099), sentrin/ sumo-specific protease (AAEL008952), proliferating cell nuclear antigen (PCNA) and DNA topoisomerase/gyrase (AAEL012584) (Figure 4). The SUMO pathway affects several cellular processes such as transport, apoptosis, and transcriptional regulation, among others [28]. Thus, in this work, we have identified a conserved protein that hypothetically plays a role in the SUMOylation pathway.

The enzyme lactoylglutathione lyase (AAEL014393) exhibited predicted functional associations with hydroxyacylglutathione hydrolase (AAEL009462), threonine dehydratase/deaminase (AAEL003568) and with the conserved hypothetical protein (AAEL000542) (Figure 5). According to the KEGG, lactoylglutathione lyase and hydroxyacylglutathione hydrolase participate in the pyruvate metabolism pathway. In addition, lactoylglutathione lyase is involved in the metabolism of threonine.

The rho guanine dissociation factor (AAEL012996) exhibited predicted functional association with rac GTPases (Cdc42, AAEL009732, AAEL015271), rab GDPdissociation inhibitor (AAEL012904), rac-GTP binding protein (AAEL001853) and GTPase_rho (AAEL013139, AAEL006786) (Figure 6). The GTPases of the Rho subfamily are involved in various signaling pathways that regulate the cell cycle progression and tissue morphogenesis $[29,30]$. It has also been demonstrated that rac GTPases participate in the Drosophila anti-parasitoid immune response [31].

Finally, although no predicted associations were found for phosphatidylethanolamine-binding protein (AAEL011268), this protein was shown to be associated with a protective effect against bacterial infection in Drosophila [32].

\section{Conclusion}

In this study, we used 2DE combined with LC-MS/MS and data mining for mapping and identifying proteins expressed in the midgut of Ae. albopictus females fed exclusively on sugar. Analyses of subproteomes such as the one performed here, permit proteins with unknown function to be assigned to specific anatomical locations. In addition, data mining allowed us to assign potential functions to these proteins based on the functional association predictions. Our results also provided, for the first time, evidence on the expression and localization of proteins that were primarily assigned as hypothetical, thereby validating previous genome sequence predictions made in Ae. aegypti. This preliminary map of the Ae. albopictus midgut proteins will allow future comparisons of gene expression from the midgut of females fed with blood, making possible the identification of proteins that are exclusively expressed under a specific feeding condition.

\section{Competing interests}

The authors declare that they have no competing interests.

\section{Authors' contributions}

JBJ, LSV and PC designed the study. LSV, ABV, CMR, and MJ performed the experimental work. LSV, PC and JBJ analyzed the data and prepared the manuscript with the critical input of MJ, GBD and CB. All authors read and approved the final manuscript.

\section{Acknowledgements}

This was supported by FAPEMIG (APQ-02093-09), FIOCRUZ-IOC, CNPq and CAPES. We thank Prof. Dr. Nildimar Honorio (Laboratório de Transmissores de Hematozoários of the Instituto Oswaldo (ruz) for kindly providing the insects.

\section{Author details}

'Laboratório de Biologia Molecular e Doenças Endêmicas, Instituto Oswaldo Cruz, FIOCRUZ, Rio de Janeiro, Brazil. 'Laboratório de Pesquisa em

Leishmaniose, Instituto Oswaldo Cruz, FIOCRUZ, Rio de Janeiro, Brazil. ${ }^{3}$ Unidade de Proteômica, Laboratório de Química de Proteínas, Instituto de Química, Universidade Federal do Rio de Janeiro, Rio de Janeiro, Brazil. ${ }^{4}$ Departamento de Engenharia de Biossistemas, Universidade Federal de São João Del Rey, Minas Gerais, Brazil. ${ }^{5}$ Laboratório de Bioquímica e Química Proteínas, Departamento de Biologia Celular, Universidade de Brasília, Brasília, Brazil.

Received: 30 September 2012 Accepted: 30 November 2012 Published: 11 December 2012

\section{References}

1. WHO: Yellow fever factsheet. Geneva: World Health Organization; 2001.

2. Hsieh $\mathrm{YH}$, Chen $\mathrm{CW}$ : Turning points, reproduction number, and impact of climatological events for multi-wave dengue outbreaks. Trop Med Int Health 2009, 14:628-638.

3. Angelini R, Finarelli AC, Angelini $P, P o C$, Petropulacos $K$, Macini $P$, Fiorentini C, Fortuna C, Venturi G, Romi R, Majori G, Nicoletti L, Rezza G, Cassone A: An outbreak of chikungunya fever in the province of Ravenna. Italy. Euro Surveill 2007, 12:E070906.1.

4. Gomes Ade C, Bitencourt MD, Natal D, Pinto PL, Mucci LF, de Paula MB, Urbinatti PR, Barata JM: Aedes albopictus in rural zone of Brazil and its implication in the wild yellow fever transmission. Rev Saude Publica 1999, 33:95-97.

5. Rai KS: Genetics of Aedes albopictus. J Am Mosq Control Assoc 1986, 2:429-436

6. Raikhel AS, Dhadialla TS: Accumulation of yolk proteins in insect oocytes. Annu Rev Entomol 1992, 37:217-251.

7. Ribeiro JM: Blood-feeding arthropods: live syringes or invertebrate pharmacologists? Infect Agents Dis 1995, 4:143-152.

8. Ribeiro JM, Francischetti IM: Role of arthropod saliva in blood feeding: sialome and post-sialome perspectives. Annu Rev Entomol 2003, 48:73-88.

9. Wasinpiyamongkol L, Patramool S, Luplertlop N, Surasombatpattana P, Doucoure S, Mouchet F, Séveno M, Remoue F, Demettre E, Brizard JP, Jouin P, Biron DG, Thomas F, Missé D: Blood-feeding and immunogenic Aedes aegypti saliva proteins. Proteomics 2010, 10:1906-1916.

10. Fontaine A, Pascual A, Diouf I, Bakkali N, Bourdon S, Fusai T, Rogier C, Almeras L: Mosquito salivary gland protein preservation in the field for immunological and biochemical analysis. Parasit Vectors 2011, 4:33.

11. Juhn J, Naeem-Ullah U, Guedes B, Majid A, Coleman J, Pimenta P, Akram W, James A, Marinotti O: Spatial mapping of gene expression in the salivary glands of the dengue vector mosquito. Aedes aegypti. Parasit Vectors 2011, 4:1

12. Sánchez-Vargas I, Scott JC, Poole-Smith BK, Franz AW, Barbosa-Solomieu V, Wilusz J, Olson KE, Blair CD: Dengue virus type 2 infections of Aedes aegypti are modulated by the mosquito's RNA interference pathway. PLOS Pathog 2009, 5:e1000299.

13. Bayyareddy K, Andacht TM, Abdullah MA, Adang MJ: Proteomic identification of Bacillus thuringiensis subsp. israelensis toxin Cry4Ba binding proteins in midgut membranes from Aedes (Stegomyia) aegypti Linnaeus (Diptera, Culicidae) larvae. Insect Biochem Mol Biol 2009, 39:279-286. 
14. Popova-Butler A, Dean DH: Proteomic analysis of the mosquito Aedes aegypti midgut brush border membrane vesicles. J Insect Physiol 2009, 55:264-272.

15. Beyenbach KW, Baumgart S, Lau K, Piermarini PM, Zhang S: Signaling to the apical membrane and to the paracellular pathway: changes in the cytosolic proteome of Aedes Malpighian tubules. J Exp Biol 2009, 212:329-340.

16. Sirot LK, Hardstone MC, Helinski ME, Ribeiro JM, Kimura M, Deewatthanawong P, Wolfner MF, Harrington LC: Towards a semen proteome of the dengue vector mosquito: protein identification and potential functions. PLOS Negl Trop Dis 2011, 5:e989.

17. Patramool S, Surasombatpattana P, Luplertlop N, Sévéno M, Choumet V, Thomas F, Missé D: Proteomic analysis of an Aedes albopictus cell line infected with Dengue serotypes 1 and 3 viruses. Parasit Vectors 2011, 4:138.

18. Cuervo P, De Jesus JB, Saboia-Vahia L, Mendonça-Lima L, Domont GB, Cupolillo E: Proteomic characterization of the released/secreted proteins of Leishmania (Viannia) braziliensis promastigotes. J Proteomics 2009, 73:79-92.

19. Neuhoff $V$, Arold N, Taube D, Ehrhardt W: Improved staining of proteins in polyacrylamide gels including isoelectric focusing gels with clear background at nanogram sensitivity using Coomassie Brilliant Blue G-250 and R-250. Electrophoresis 1988, 9:255-262.

20. De Jesus JB, Cuervo $P$, Junqueira M, Britto C, Silva-Filho FC, Soares MJ, Cupolillo E, Fernandes O, Domont GB: A further proteomic study on the effect of iron in the human pathogen Trichomonas vaginalis. Proteomics 2007, 7:1961-1972.

21. Jensen $L$, Kuhn M, Stark M, Chaffron S, Creevey C, Muller J, Doerks T, Julien P, Roth A, Simonovic M, Bork P, von Mering C: STRING 8-a global view on proteins and their functional interactions in 630 organisms. Nucleic Acids Res 2009, 37:D412-D416.

22. Szklarczyk D, Franceschini A, Kuhn M, Simonovic M, Roth A, Minguez $P$, Doerks T, Stark M, Muller J, Bork P, Jensen LJ, von Mering C: The STRING database in 2011: functional interaction networks of proteins, globally integrated and scored. Nucleic Acids Res 2011, 39:D561-D568.

23. Tchankouo-Nguetcheu S, Khun H, Pincet L, Roux P, Bahut M, Huerre M, Guette C, Choumet V: Differential protein modulation in midguts of Aedes aegypti infected with chikungunya and dengue 2 viruses. PLoS One 2010, 5:e13149.

24. Reynolds J, Poelchau MF, Rahman Z, Armbruster PA, Denlinger DL: Transcript profiling reveals mechanisms for lipid conservation during diapause in the mosquito. Aedes albopictus. J Insect Physiol 2012, 58:966-973.

25. Sanders HR, Evans AM, Ross LS, Gill SS: Blood meal induces global changes in midgut gene expression in the disease vector. Aedes aegypti. Insect Biochem Mol Biol 2003, 33:1105-1122.

26. Nair PM, Park SY, Choi J: Expression of catalase and glutathione S-transferase genes in Chironomus riparius on exposure to cadmium and nonylphenol. Comp Biochem Physiol C Toxicol Pharmacol 2011, 154:399-408.

27. Nair PM, Choi J: Characterization and transcriptional regulation of thioredoxin reductase 1 on exposure to oxidative stress inducing environmental pollutants in Chironomus riparius. Comp Biochem Physiol B Biochem Mol Biol 2012, 161:134-139.

28. Hay RT: SUMO: A history of modification. Mol Cell 2005, 18:1-12.

29. Settleman J: Rac 'n Rho: the music that shapes a developing embryo. Dev Cell 2001, 1:321-331.

30. Pirraglia C, Myat MM: Genetic regulation of salivary gland development in Drosophila melanogaster. Front Oral Biol 2010, 14:32-47.

31. Xavier MJ, Williams MJ: The Rho-family GTPase Rac1 regulates integrin localization in Drosophila immunosurveillance cells. PLoS One 2011, 6:e19504.

32. Reumer A, Bogaerts A, Van Loy T, Husson SJ, Temmerman L, Choi C, Clynen E, Hassan B, Schoofs L: Unraveling the protective effect of a Drosophila phosphatidylethanolamine-binding protein upon bacterial infection by means of proteomics. Dev Comp Immunol 2009, 33:1 186-1195.

doi:10.1186/1756-3305-5-290

Cite this article as: Saboia-Vahia et al:: Protein expression in the midgut of sugar-fed Aedes albopictus females. Parasites \& Vectors 2012 5:290.

\section{Submit your next manuscript to BioMed Central and take full advantage of:}

- Convenient online submission

- Thorough peer review

- No space constraints or color figure charges

- Immediate publication on acceptance

- Inclusion in PubMed, CAS, Scopus and Google Scholar

- Research which is freely available for redistribution

Submit your manuscript at www.biomedcentral.com/submit
C Biomed Central 